\title{
Remazol Brilliant Blue Degradation Using Contact Glow Discharge Electrolysis Reactor with Air Injection and $\mathrm{NaCl}$ Solution
}

\author{
Fikri Averous ${ }^{1, *}$, Dwiputra Muhammad Zairin ${ }^{1}$, and Nelson Saksono ${ }^{1}$ \\ ${ }^{1}$ Department of Chemical Engineering, Universitas Indonesia, Depok 16424, West Java - Indonesia
}

\begin{abstract}
Remazol Brilliant Blue dye waste is one of the liquid waste produced from the textile industry and harmful to the environment. Contact Glow Discharge Electrolysis (CGDE) method is an effective method to degrade dye waste by producing $\mathrm{OH}$ radicals which will be used in liquid waste degradation process. This study aims to determine the effect of anode depth, temperature, and flow rate of air injection on the production of hydroxyl radicals and dye degradation of Remazol Brilliant Blue. This research was conducted in batch reactor with electrolyte $\mathrm{NaCl} 0,03$ $\mathrm{M}$. Variation which done is anode depth which is $0,5 \mathrm{~cm} ; 2 \mathrm{~cm} ; 4 \mathrm{~cm}$, temperature of $40^{\circ} \mathrm{C} ; 50^{\circ} \mathrm{C}$; $60^{\circ} \mathrm{C}$, and air injection flow rate of $0 \mathrm{lpm}$ and $2.5 \mathrm{lpm}$. The research was conducted by voltage current characteristic test, hydroxyl radical production test, and dye degradation test. Remazol Brilliant Blue degradation reached $96.15 \%$ within 30 minutes where the tension was $750 \mathrm{~V}, 0.03 \mathrm{M}$ $\mathrm{NaCl}$ solution concentration, $\mathrm{Fe}^{2+} 40 \mathrm{ppm}, 2 \mathrm{~cm}$ anode depth, $50^{\circ} \mathrm{C}$ temperature, and $2.5 \mathrm{lpm}$ air injection flow rate.
\end{abstract}

\section{Introduction}

The textile industry has an important role in the world since the product is one of the basic human needs. The existence of textile industry in Indonesia is not only in large scale but also in the form of household scale or small medium enterprises (SMEs) for the coloring process. Due to the limitations that exist within the business process, most of the waste from this textile dyeing process is discharged directly into the environment causing environmental pollution and lifethreatening of flora and fauna which consume wastecontaminated water [1].

One method which has a high effectiveness to handle waste is Contact Glow Discharge Electrolysis (CGDE) or commonly referred to as plasma electrolysis. This method is well known to degrade waste, especially liquid waste. This method will form a plasma that can degrade the compounds contained within the waste. The plasma will be formed in solvent on the electrode. The formed plasma is a result of the high potential difference between the two electrodes to form highly-reactive radical compounds, for instance radicals $\bullet \mathrm{OH}$ and radical $\bullet \mathrm{H}$ [2]. This method of plasma electrolysis has a much higher yield value than conventional electrolysis since the radical compounds that are formed will evoke a remarkable chemical reaction in the solution.
However, since this method requires high energy consumption, it is necessary to make some adjustments to make this technology more applicable to the SMEs. One of the things that can be used is air injection. With the air injection, the process of forming a plasma shell is more easily formed. Air injection can stabilize the gas sheath, so the plasma is more easily formed. The gas shell is formed through the process of evaporation of $\mathrm{H}_{2} \mathrm{O}$ due to joule heating effect. The amount of energy used in the evaporation process is $95 \%$ of the total energy. Due to the air injection, the gas shell can form stable, ionization reactions are also easier to reduce the energy in the evaporation process and reduce the energy consumption required [3]. In addition to the use of air injection, the depth of anode and temperature can also affect the energy consumption. The deeper the electrodes are dyed, the larger the plasma is formed and is directly proportional to the formed radical species. On the other hand, higher temperatures can lower the energy consumption and make the plasma produced becomes larger [2].

\section{Experimental Section}

\subsection{Materials}

The material that are used is Brilliant Blue Remazol compound as waste, $\mathrm{Fe}_{2} \mathrm{SO}_{4} \cdot 7 \mathrm{H}_{2} \mathrm{O}$ as additional iron salt, $\mathrm{NaCl}$ as electrolyte solution, and $\cdot \mathrm{OH}$ radical

Corresponding author: nelsonsaksono@gmail.com 
production test that is performed by permanganometric titration method using $\mathrm{KMnO}_{4}, \mathrm{H}_{2} \mathrm{SO}_{4}$, and $\mathrm{Na}_{2} \mathrm{C}_{2} \mathrm{O}_{4}$.

\subsection{Instrumentation}

The primary tool used in this research is Contact Glow Discharge Electrolysis (CGDE) reactor with the schematic of the tool which can be seen in Figure 1. The electric circuit used consists of transformer, regulator slide, and bridge diode. The reactor is equipped with a cooling water circulation system on the outside to keep the temperature of the solution. The type of anode used within the tool is tungsten, while the cathode used is stainless steel. In the anode section, a glass sheathing is provided and connected to the air injection to reduce the energy consumption.

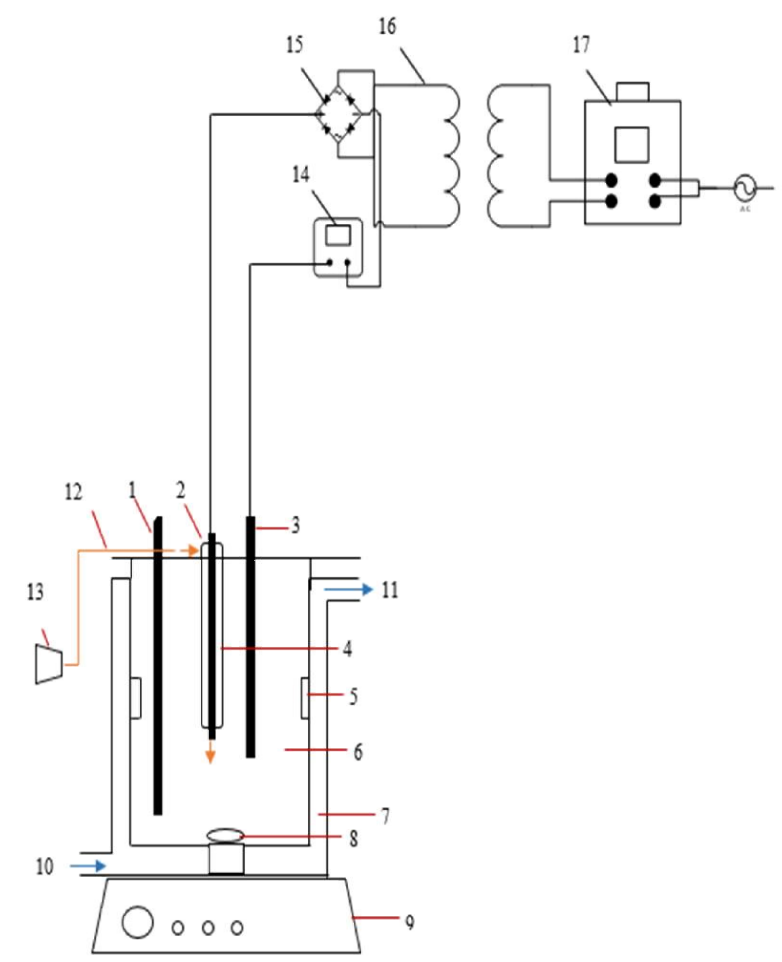

1. Thermometer

2. Anode

3. Cathode

4. Quartz Glass

5. Baffle

6. Waste Solution

7. Cool Water Container

8. Magnetic bar

9. Magnetic stirrer

10. Cooling Water Input

11. Cooling Water Output

12. Air Injection Input

13. Compressor

14. Multimeter

15. Dioda Bridge

16. Transformer

17. Slide Regulator

Fig. 1. Configuration of Plasma Electrolysis Instrumentation

\subsection{Procedure}

This research begins with characterization of the voltage-current to find out the relationship between the voltage and current that are generated during the research process, and knowing the tension of how the plasma is formed. Variations used at this stage are the depth of the anode and the use of air injection.
In the measurement of hydroxyl radical, electrolyte solution is used by not mixing it with the Remazol Brilliant Blue 'batik' dye waste. The measurement of hydroxyl radical is undertaken by identifying the concentration of $\mathrm{H}_{2} \mathrm{O}_{2}$. Then, the measurement of $\mathrm{H}_{2} \mathrm{O}_{2}$ concentration can be used as an indicator of the number of hydroxyl radicals that are present within the sample. The method that is used to measure the concentration of $\mathrm{H}_{2} \mathrm{O}_{2}$ is the permanganometric titration method.

Furthermore, the Brilliant Blue Remazol degradation is performed for 30 minutes and analyzed using UV-Vis spectrophotometer with anode depth variation, temperature, and air injection usage. The degradation value is calculated by Equation 1 .

Percentage of degradation $(\%)=\frac{c_{t}-C_{0}}{\mathrm{c}_{0}} \times 100$

With :

$\mathrm{C}_{0} \quad=$ Initial Concentration (ppm)

$\mathrm{C}_{\mathrm{t}} \quad=$ Final Concentration (ppm)

\section{Results and Discussion}

\subsection{Effect of Anode Depth in Characterization of the Voltage-Current}

Figure 2 shows that the deeper the anode is dyed, the higher the voltage and current become because it takes more energy to maintain the stability of the plasma that is disturbed due to the hydrostatic force and buoyant force when the anode is being dyed.

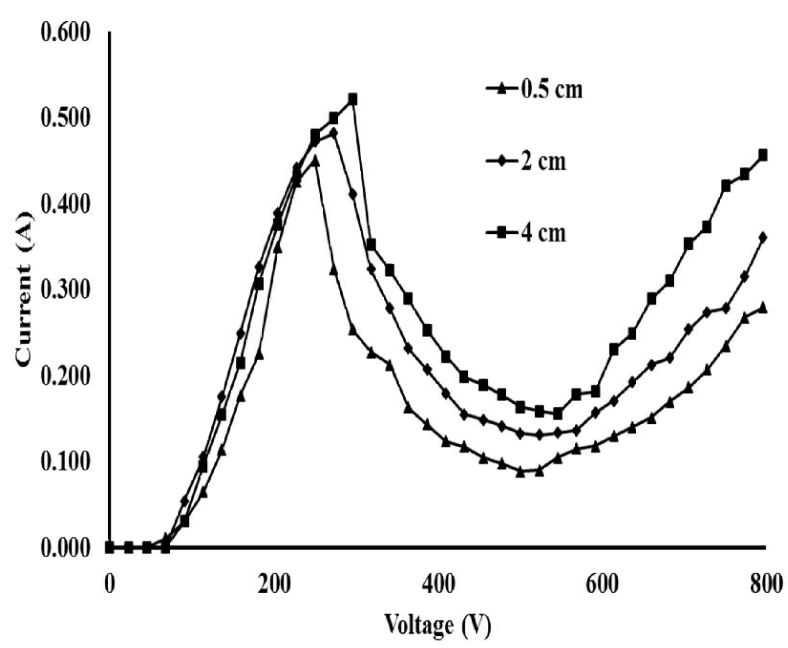

Fig. 2. Characterization of Volage-Current with Variation of Anode Depth

In Figure 3, related with the addition of air injection, the $V_{B}$ and $V_{D}$ values are smaller than those that are without the addition of air injection. With the addition of air injection, the gas that shrouds for the formation of plasma will be more easily formed because the addition can accelerate the process of plasma stabilization since the plasma is ionized gas, 
thus, it will be easier to be formed if the media where the formation of plasma taken place is gas.

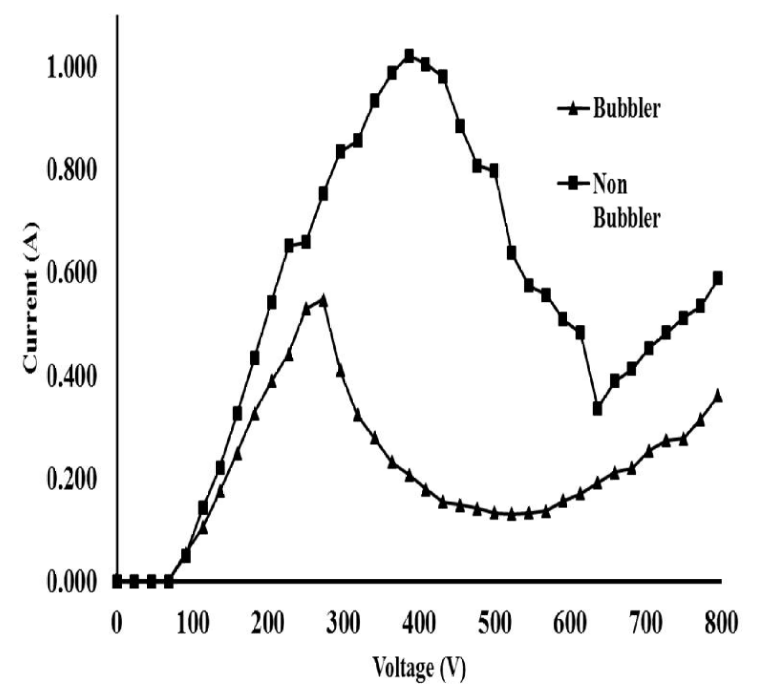

Fig. 3. Characterization of Volage-Current with Variation of Air Injection Flow Rate

\subsection{Effect of Anode Depth in Hydroxil Radical Production}

- $\mathrm{OH}$ radical is a compound that has low residence time making so that it is difficult to measure its existence in a solution. Therefore, the $\mathrm{H}_{2} \mathrm{O}_{2}$ compound, which becomes the recombinant compound of the $\cdot \mathrm{OH}$ radical, is taken as an indicator of the presence of $\bullet \mathrm{OH}$ radicals. Test of production of hydroxyl radical is undergone without mixing the waste by using permanganometric titration analysis method.

Figure 4 shows that the deeper the anode's depth is, the higher the radical production of $\bullet \mathrm{OH}$ increases because the contact between the plasma and the electrolyte solution will be more intense. It appears that at a depth of $0.5 \mathrm{~cm}$, the radical production of $\cdot \mathrm{OH}$ becomes small since the contact between plasma and electrolyte solution is not effective on the surface.

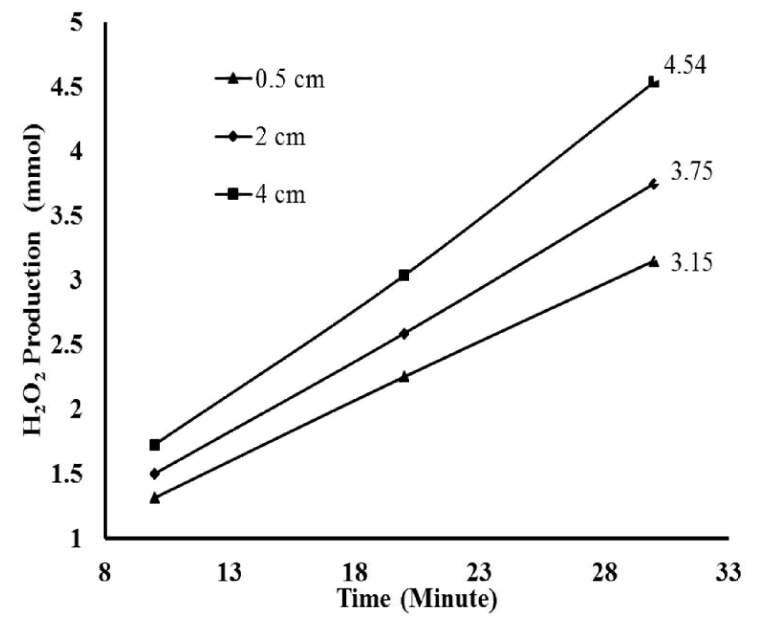

Fig. 4. Effect of Electrolyte Concentration to $\mathrm{H}_{2} \mathrm{O}_{2}$ Production with $750 \mathrm{~V}$

\subsection{Effect of Temperature in Hydroxil Radical Production}

Figure 5 shows that the higher the temperature is, the more hydroxyl radical production will be, the higher the temperature will accelerate the solution to reach its boiling point so it will turn into the gas phase and will enhance the formation of the gas shell around the anode. This gas shroud is the stage of plasma formation so that at the higher temperatures, it will enlarge the plasma flame. At $60^{\circ} \mathrm{C}$ the decomposition reaction of $\mathrm{H}_{2} \mathrm{O}_{2}$ will occur faster so that quantity of $\mathrm{H}_{2} \mathrm{O}_{2}$ will be less quantified.

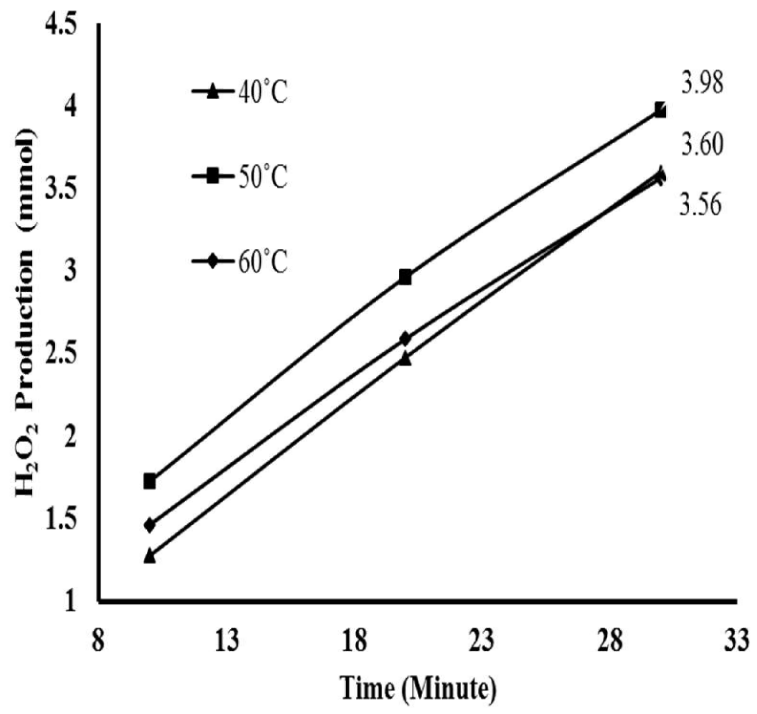

Fig. 5. Effect of Temperature to $\mathrm{H}_{2} \mathrm{O}_{2}$ Production with $750 \mathrm{~V}$

\subsection{Effect of Air Injection Flow Rate in Hydroxil Radical Production}

Figure 6 shows that $\cdot \mathrm{OH}$ production without bubbler results in more than those with a bubbler. This is because those without the use of bubbler has much higher energy than those with the bubbler. This higher energy causes a bigger plasma flame, and with a larger plasma produces more $\cdot \mathrm{OH}$ as compared to the lesser plasma.

Conducted research by equating the energy consumption needed to see the effectiveness of using the bubbler. Figure 6 shows that the use of a bubbler with equalized energy produces more $\cdot \mathrm{OH}$ radicals than those without the use of a bubbler. This is because the air injections contribute to the production of radical $\mathrm{OH} \bullet$ that can be seen in the reaction as follows [4]

$$
\begin{aligned}
& \mathrm{e}+\mathrm{O}_{2} \rightarrow \mathrm{O} \bullet+\mathrm{O} \bullet+\mathrm{e} \\
& \mathrm{O} \bullet+\mathrm{H}_{2} \mathrm{O} \rightarrow \cdot \mathrm{OH}+\bullet \cdot \mathrm{OH}
\end{aligned}
$$




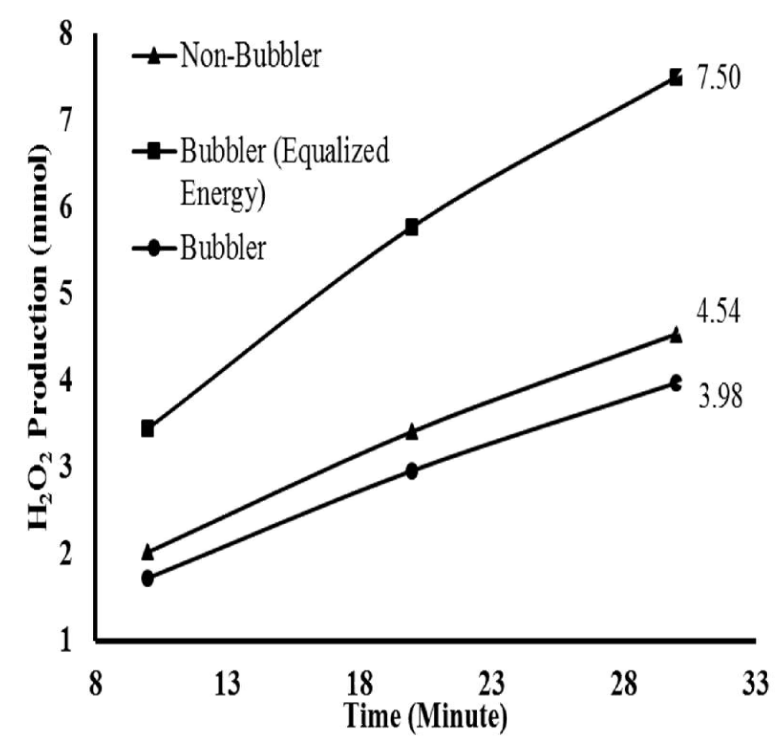

Fig. 6. Effect of Air Injection Flow Rate to $\mathrm{H}_{2} \mathrm{O}_{2}$ Production

Table 1 shows that the use of a bubbler with the same voltage as the non-bubbler would suppress a very significant energy consumption but with less $\mathrm{H}_{2} \mathrm{O}_{2}$ production than non-bubbler. This is because the use of bubbler will facilitate the process of plasma formation, thereby reducing the energy consumption required [5]. Testing the use of bubbler with the equalized energy proved to produce more $\mathrm{H}_{2} \mathrm{O}_{2}$ from non-bubbler.

Table 1. Production of $\mathrm{H}_{2} \mathrm{O}_{2}$ and Energy Consumption with Variation of Air Injection Flow Rate in $30^{\text {th }}$ Minute

\begin{tabular}{ccc}
\hline $\begin{array}{c}\text { Air Injection } \\
\text { Flow Rate } \\
\text { (lpm) }\end{array}$ & $\begin{array}{c}\mathbf{H}_{2} \mathbf{O}_{\mathbf{2}} \text { Production } \\
\text { (mmol) }\end{array}$ & $\begin{array}{c}\text { Energy } \\
\text { (kJ) }\end{array}$ \\
\hline 2.5 & 3.98 & 155.89 \\
\hline 0 & 4.54 & 566.25 \\
\hline $\begin{array}{c}2.5 \\
\text { (Equalized Energy) }\end{array}$ & 7.50 & 567.00 \\
\hline
\end{tabular}

\subsection{Effect of Anode Depth in Degradation of Remazol Brilliant Blue}

Table 2 shows that deeper dyed anodes can degrade the Remazol Brilliant Blue better. Degradation with anode depth of $4 \mathrm{~cm}$ in the 30 th minute reached $97.06 \%$. This is in accordance with the test of the production of hydroxyl radical at a depth of $4 \mathrm{~cm}$ which has the highest production of hydroxyl radicals.

The degradation results at a depth of $4 \mathrm{~cm}$ are influenced by the contacted anode directly with the contact area between the plasma and the electrolyte solution. Degradation at anode depth of $2 \mathrm{~cm}$ and $4 \mathrm{~cm}$ is greater than $0.5 \mathrm{~cm}$ because it is related to contact intensity between radical $\bullet \mathrm{OH}$ with electrolyte solution in plasma-liquid interfase zone. Whereas at the depth of the anode $0.5 \mathrm{~cm}$ plasma is formed on the surface of the solution which causes most of the plasma to be in contact with the solution on the surface. Plasma in contact with the solution on the surface is ineffective so that the resulting hydroxyl radical becomes less and makes the degradation not maximum [6]. The larger the plasma contact with the solution the more electrons can be excited and cause the collision between the gas molecule and the greater the electron.

Table 2. Effect of Anode Depth on Remazol Brilliant Blue Degradation

\begin{tabular}{cccc}
\hline \multirow{2}{*}{$\begin{array}{c}\text { Time } \\
\text { (Minute) }\end{array}$} & $\mathbf{0 . 5} \mathbf{~ c m}$ & $\mathbf{2} \mathbf{~ c m}$ & $\mathbf{4} \mathbf{~ c m}$ \\
\hline 0 & 0.00 & 0.00 & 0.00 \\
\hline 3 & 39.51 & 41.91 & 52.90 \\
\hline 6 & 64.81 & 67.27 & 69.88 \\
\hline 8 & 71.23 & 73.55 & 76.79 \\
\hline 10 & 81.22 & 82.88 & 83.16 \\
\hline 15 & 86.69 & 88.35 & 87.44 \\
\hline 20 & 91.61 & 93.41 & 93.81 \\
\hline 25 & 93.49 & 95.02 & 95.42 \\
\hline 30 & 94.87 & 96.15 & 97.06 \\
\hline
\end{tabular}

\subsection{Effect of Temperature in Degradation of Remazol Brilliant Blue}

Table 3 shows that the best Brilliant Blue Remazol degradation results in temperature variations of $50^{\circ} \mathrm{C}$. This is in accordance with the previous test of hydroxyl radical production test, which in the test proves that the production of the most hydroxyl radical is in temperature variation of $50^{\circ} \mathrm{C}$. It can be seen that the amount of hydroxyl radical formed will affect the number of moles of the dye Remazol Brilliant Blue degraded.

The result of degradation with this temperature variation shows that the higher the temperature the degradation performance will be more effective. However, in temperature variation $60^{\circ} \mathrm{C}$ degradation performance is lower than $50^{\circ} \mathrm{C}$, this is due to decomposition reaction $\mathrm{H}_{2} \mathrm{O}_{2}$ to $\mathrm{H}_{2} \mathrm{O}$ and $\mathrm{O}_{2}$ [7]. This reaction proceeds more rapidly with higher operating temperatures [8]. The higher the temperature speed up the process of Joule Heating so that the process of plasma formation is faster and the plasma is formed larger. 
Table 3. Effect of Temperature on Remazol Brilliant Blue Degradation

\begin{tabular}{cccc}
\hline \multirow{2}{*}{$\begin{array}{c}\text { Time } \\
\text { Minute) }\end{array}$} & \multicolumn{3}{c}{ Degradation (\%) } \\
\cline { 2 - 4 } & $\mathbf{4 0}^{\circ} \mathbf{C}$ & $\mathbf{5 0}^{\circ} \mathbf{C}$ & $\mathbf{6 0}^{\circ} \mathbf{C}$ \\
\hline 0 & 0.00 & 0.00 & 0.00 \\
\hline 3 & 31.46 & 44.26 & 33.85 \\
\hline 6 & 40.73 & 68.60 & 54.15 \\
\hline 8 & 55.82 & 74.62 & 69.44 \\
\hline 10 & 60.49 & 83.57 & 75.97 \\
\hline 15 & 78.11 & 88.82 & 83.03 \\
\hline 20 & 81.86 & 93.68 & 90.04 \\
\hline 25 & 87.19 & 95.22 & 93.60 \\
\hline 30 & 91.60 & 96.30 & 95.18 \\
\hline
\end{tabular}

\subsection{Effect of Air Injection Flow Rate in Degradation of Remazol Brilliant Blue}

Table 4 shows that the degradation results with variations in the airflow injection rate are in accordance with the results of the hydroxyl radical production test which shows that the best results are in variations in the use of bubblers with equalized energy. The use of air injections contributes to radical specimens that may be helpful in the Remazol Brilliant Blue degradation process [9]. The oxygen contained in the injected air produces a hydroxyl radical. [4]. The radical compounds have different oxidation values and the $\mathrm{O} \bullet$ radical has a high value [10]. The reaction equation for the addition of air injection is as follows:

$$
\begin{aligned}
& \mathrm{e}^{-}+\mathrm{O}_{2} \rightarrow \mathrm{O} \bullet+\mathrm{O} \bullet+\mathrm{e}^{-} \\
& \mathrm{O} \bullet+\mathrm{H}_{2} \mathrm{O} \rightarrow \bullet \mathrm{OH}+\bullet \mathrm{OH} \\
& \bullet \mathrm{OH}+\mathrm{O}_{2} \rightarrow \mathrm{H}_{2} \mathrm{O} \bullet+\mathrm{O} \bullet
\end{aligned}
$$

Table 4. Effect of Air Flow Injection Rate on Remazol Brilliant Blue Degradation

\begin{tabular}{cccc}
\hline \multirow{2}{*}{$\begin{array}{c}\text { Time } \\
\text { (Minute) }\end{array}$} & $\mathbf{0 ~ l p m}$ & $\mathbf{2 . 5} \mathbf{~ l p m}$ & $\begin{array}{c}\mathbf{2 . 5} \text { lpm } \\
\text { (Equalized } \\
\text { Energy) }\end{array}$ \\
\cline { 2 - 4 } & 0.00 & 0.00 & 0.00 \\
\hline 0 & 65.85 & 44.26 & 72.36 \\
\hline 3 & 81.55 & 68.60 & 88.32 \\
\hline 6 & 89.15 & 74.62 & 93.59 \\
\hline 8 & 93.27 & 83.57 & 95.88 \\
\hline 10 & 96.20 & 88.82 & 97.79 \\
\hline 15 & 97.46 & 93.68 & 98.05 \\
\hline 20 & 98.01 & 95.22 & 98.80 \\
\hline 25 & 98.36 & 96.30 & 99.43 \\
\hline 30 & & &
\end{tabular}

\section{Conclusion}

This experiment has proven that air injections in the CGDE process decrease the production of hydroxyl radicals but can suppress the energy consumption required in the process. Remazol Brilliant Blue degradation for 30 minutes achieved $96.30 \%$ at $750 \mathrm{~V}$, anode depth of $2 \mathrm{~cm}$, initial concentration of waste 150 ppm, temperature $50^{\circ} \mathrm{C}$, with $2.5 \mathrm{lpm}$ air injection.

This research was partially funded by "Hibah Publikasi Internasional Terindeks Tugas Akhir Mahasiswa Universitas Indonesia 2018 Contract 2500/UN2.R3.1/HKP.05.00/2018" from Directorate Research and Community Service Universitas Indonesia. The authors declare no competing interests or any conflicts of financial interests.

\section{References}

1. Wang, L. Plasma Chemistry and Plasma Processing 29, 241-250 (2009)

2. N. Saksono, B. Priyogoreno, E. F. Karamah and S. Kartohardjono, Journal of Environmental Science and Technology 6, 1, 41-49 (2013)

3. Jiang, B., Zheng, J., Qiu, S., Wu, M., Zhang, Q., Yan, Z., \& Xue, Q. Chemical Engineering Journal, 236, 348-368 (2014)

4. Yasuoka, K. and Sato, K. International Journal of Plasma Environmental Science and Technology, 3(1), 22-27 (2010)

5. Jin, Xinglong, Wang, Xiaoyan, Wang, Qingfeng, Yue, Junjie, \& Cai, Yaqi. Water Science \& Technology, 62, 7 (2010)

6. Bismo, S., Irawan, K., Karamah, E., \& Saksono, N. Journal of Chemistry \& Chemical Engineering 7 (2013)

7. Jin, X., Wang, X., Yue, J., \& Cai, Y. Electrochimica Acta, 56, 925-928 (2010)

8. Gao, J., Wang, X., Hu, Z., Deng, H., Hou, J., Lu, X. \& Kang, J. Water Research, 37, 267-272 (2003)

9. Ruma, Habib, M.A., Sakugawa, T. Journal of Renewable Energy and Environmental Engineering, 3, 3 (2015)

10. Augusto, O., \& Sayuri, M. Free Radical Biomedicine, 1 (2011) 